\title{
Prevention is Better than Cure: An Application of Big Data and Geospatial Technology in Mitigating Pandemic
}

\author{
Pooja Shah ${ }^{1}$ (D) . Chetan R. Patel ${ }^{1}$
}

Received: 17 April 2020 / Revised: 26 May 2020 / Accepted: 29 May 2020 / Published online: 6 June 2020

(C) Indian National Academy of Engineering 2020

\begin{abstract}
COVID-19 has been a severe threat to city's dense ecosystem and has collapsed the urban life. These spread has raised question on urban health infrastructure and coping capacity. To maintain social distance and providing community with essentials is a challenging task for government and city planners in dense urban area. Spatial mapping of resources, patients, medical infrastructure, potential open space, places which can be turned to quarantine centers, etc. has been done using GIS for city of Surat. Larger open spaces within the urban fabric are identified to implement emergency services and evacuation protocols. This tool will defiantly be helpful to the city administration in maintaining the cluster, quarantine tracking of the infected community and flow of daily essential, supply chain in cities with restriction in the infected cluster. Even having better technology to fight against any pandemic, geospatial technology will help to prevent the pandemic to spread further and hence, it is known as prevention is better then cure.
\end{abstract}

Keywords COVID-19 · Geospatial techniques · Urban planning · Cluster quarantine

\section{Background}

Recently, geospatial technique has been used as boom word in the field of technology and science. When the world is facing such a treacherous global outbreak COVID-19, the question that arises in the mind of researchers is that how can we use out technologies as boon. The pandemic of the 2019 novel coronavirus disease (COVID-19) has caused more than 1,600,000 people infected and around one lakh of deaths (Coronavirus Disease 2020). Currently, the number of infections and deaths is still increasing rapidly. COVID19 seriously threatens human health, production, life, social functioning and international relations. Geographic understanding is essential in detecting, understanding and responding to any infectious disease outbreak specifically in pandemics such as coronavirus disease 2019 (COVID19). Even with the well-known technology, the pandemic can be cured but can be better way prevented by geospatial

Pooja Shah

poojabshah2512@gmail.com

Chetan R. Patel

chetanrpatel@rediffmail.com

1 Urban Planning Section, Civil Engineering Department, SVNIT, Surat, Gujarat, India technology; hence, it is known as the technology for prevention of spread of pandemic. This paper will demonstrate how this technology will be helpful in mapping, prediction and understanding behavior of cluster under quarantine. For the understanding of technology, Surat is considered as the case. This tool will defiantly be helpful to the city administration in maintaining the cluster, quarantine tracking of the infected community and flow of daily essential, supply chain in cities with restriction in the infected cluster including mongering of the same.

\section{Application of Geospatial Technology in Mitigating Pandemic}

In the battle against COVID-19, geographic information systems (GIS) and huge information innovations have assumed a significant job in numerous angles. GIS encourages disease transmission experts to delineate event against various parameters including socioeconomics, the earth, geologies and past events to comprehend the starting point of episodes, its spread example and its power to execute control, preventive, and reconnaissance measures. General wellbeing organizations, arrangement creators and executives need GIS to comprehend flare-up designs progressively to recognize in 
danger populaces and plan focused on mediation, for example, assess accessible offices or increment social insurance limits. Likewise, there is a requirement for compelling correspondence among other supporting organizations and residents to guarantee a planned reaction.

Kamel Boulos and Geraghty (2020) focus and portray a scope of functional on the web/versatile GIS and mapping dashboards and applications for following the 2019/2020 coronavirus pandemic and related situations as they develop far and wide. A portion of these dashboards and applications are getting information refreshes in close ongoing (at the hour of composing), and one of them is intended for singular clients (in China) to check if the application client has had any nearby contact with an individual affirmed or suspected to have been contaminated with SARS-CoV-2 in the ongoing past. They have likewise referenced extra ways GIS can bolster the battle against irresistible sickness flareups and pestilences. During the COVID-19 flare-up, mapdriven dashboards, for example, the ones by Johns Hopkins CSSE, the WHO and Early Alert Inc., have turned into a web sensation themselves, advising both the general population and wellbeing experts. Yet, dashboards are only the start of how GIS and area advancements can bolster the battle against irresistible diseases. Arab-Mazar et al. (2020) have exhibited instances of COVID-19 in Iran and how the specialists have brought choices to close down nearby ventures and support social separating. Time-empowered maps can uncover how diseases spread after some time and where you might need to target mediations. COVID-19 disproportionally impacts certain socioeconomics, for example, the old and those with fundamental wellbeing conditions. Mapping social helplessness, age, and different elements assist you with observing in danger gatherings and areas you serve. Guide offices, workers or residents, clinical assets, hardware, products, and administrations to comprehend and react to present and potential effects of COVID-19. Utilize intuitive Web maps, dashboard applications, and Story Maps to help quickly impart your circumstance (coronavirus: How enterprises are using GIS to track COVID-19 impact, IT News, ET CIO, n.d.).

GIS has created and developed moderately rapidly and has a total innovative course for information planning, stage development, model development, and guide creation. Be that as it may, for the battle against the across the board pandemic, the fundamental test is discovering techniques to change customary specialized strategies and improve speed and exactness of data arrangement for social administration. At the information level, in the period of enormous information, information no longer come fundamentally from the legislature yet are accumulated from progressively various ventures. Therefore, the utilization of GIS faces troubles in information securing and the combination of heterogeneous information, which requires governments, organizations, and scholarly establishments to together advance the plan of pertinent approaches. At the specialized level, spatial investigation strategies for large information are in the command. At present and for quite a while later on, the advancement of GIS ought to be fortified to frame an information driven framework for fast information procurement, which implies that GIS ought to be utilized to strengthen the social activity parameterization of models and techniques, particularly when offering help for social administration (Zhou et al. 2020).

\section{Mapping of Inventories}

The effects of the worldwide COVID-19 pandemic are still being understood; however, it seems clear that this emergency will make a blemish on urban areas, truly and socially, that will resound for ages. The COVID-19 pandemic has as of now fundamentally changed urban life. The number of individuals moving around has dropped to uncommonly low levels. The destiny of a large number of private ventures and laborers that make urban focuses work is not yet decided (van den Berg 2020). While the city planners are still struggling to maintain balance between logistic planning and resource management, dense urban built up, affordable housing and other factors are challenging the planners to find out potential site for COVID-19 patients and quarantine.

\section{Data Visualization and Adaptation}

There are various dashboards around the globe for monitoring and anticipation of COVID-19 spread. Legger (2020) demonstrated data smart solutions practiced by various government across the world to effectively fight COVID-19. The article emphasis on how mapping resources and assets provide potential solution to the community. Indian government has also launched Aarogya Setu App to get information regarding individual's vulnerability to COVID-19. This app records details like location, demographic details, travel history and contact with COVID-19 positive patient. This app can be downloaded by the smartphone users in India. The app is boon for the citizens of India, but the challenge still remains for decision makers as, out of total of 135 crores population of India, it has been downloaded only in 9.8 crores smartphones (Aarogya Setu app downloaded in 9.8 crore smartphones-the New Indian Express, n.d.). Decision makers require integration of the demographic data, spatial data of individuals, locations of essential resources, road network density, population density, etc. to identify shortest route, nearby facilities and potential quarantine centers. Such datasets can be analyzed on any open source or commercial geospatial software. Looking into the global pandemic, FEMA and ESRI are providing free access to data mapping 
technology in response to COVID-19 till August 2020. The predicting strength of the software is explored by developing model to predict the cases of COVID-19 using explanatory variables like population density, building density, building heights and types of use of land like housing, commercial or industrial and positive cases of COVID based on above parameters the prediction model will help to show the probable area of containment Using this model, the severity of the pandemic can be tracked and can be monitored to avoid further spread of diseases.

\section{Methodology}

In the present research framework, Surat City of Gujarat has been considered as study area. Surat is a city located on the western part of India in the state of Gujarat. It is one of the most dynamic city of India with one of the fastest growth rate due to immigration from various part of Gujarat and other states of India (SMC 2020). Surat is mainly known for its textile and diamond market. The people engaged in these industries are majorly daily wage workers. Coping with capacity to suffice the needs of all migrants, labors along with maintaining social distance and providing accommodation has to be the need of the hour. Application of GIS has been used for spatially Mapping Patients, Hospitals, Open Spaces in case of emergency.

The first stage is designing of research statement "Integration of spatial database for policy planning of potential mapping, essential services to prevent spread of COVID-19". Vis-à-vis literature state of art was carried out to understand the global geospatial methods adopted by policy makers and administration in response to COVID-19. Research gaps were found keeping in mind the limitation due to COVID19. Formulation of research question such as what is land suitability, why it is required and what are the parameter or criteria that affect the land suitability were taken up to make resilient policies against COVID-19. Land-use map of Surat city is prepared to identify available land. This is done by taking satellite image and analyzing in ArcMap. Next step is to identify parameters that affect the land suitability and preparation of factor maps. This criteria or factor maps are converted in to raster map so that it can be classified into number of classes. The next step is to give the suitable score to each class of factors. This score ranged from low suitability to high suitability; the higher the score, the more suitable the land is. The next step is to give the weight to each criteria map.

To prepare land severity map, a spatial tool known as weighted sum is used which gives the final severity score to each pixel. Then, the score is divided into various part with high score indicating highest severity and low score indicating less severity. Based on the suitability score map is divided into various classes. Flow chart for methodology adopted in this study is shown in Fig. 1.

Area severity analysis for present study is carried out through weighted sum overlay technique in GIS. Factor map of various parameters have to be overlaid. For preparing factor map nearest distance is calculated through Euclidean distance tool of spatial analyst in ArcGIS to check the influence of each parameter. Then, the nearest distance tiff file is reclassified into five classes and score is given on one-five rank. For population density, land cover, elevation and slope map, Euclidean distance is not required. In socio-economic criteria, less population density, less travel time to commercial area, minimum distance to education facilities from residential area and maximum potential of growth node, for utilities, minimum distance from major roads, minor roads, railway lines, airport and major transportation center, in environment, area which is nearby stream and water treatment plant and far from sewage treatment plant and landfill site and as a physical criteria, open land, agriculture land and sparse vegetation, less slope and more

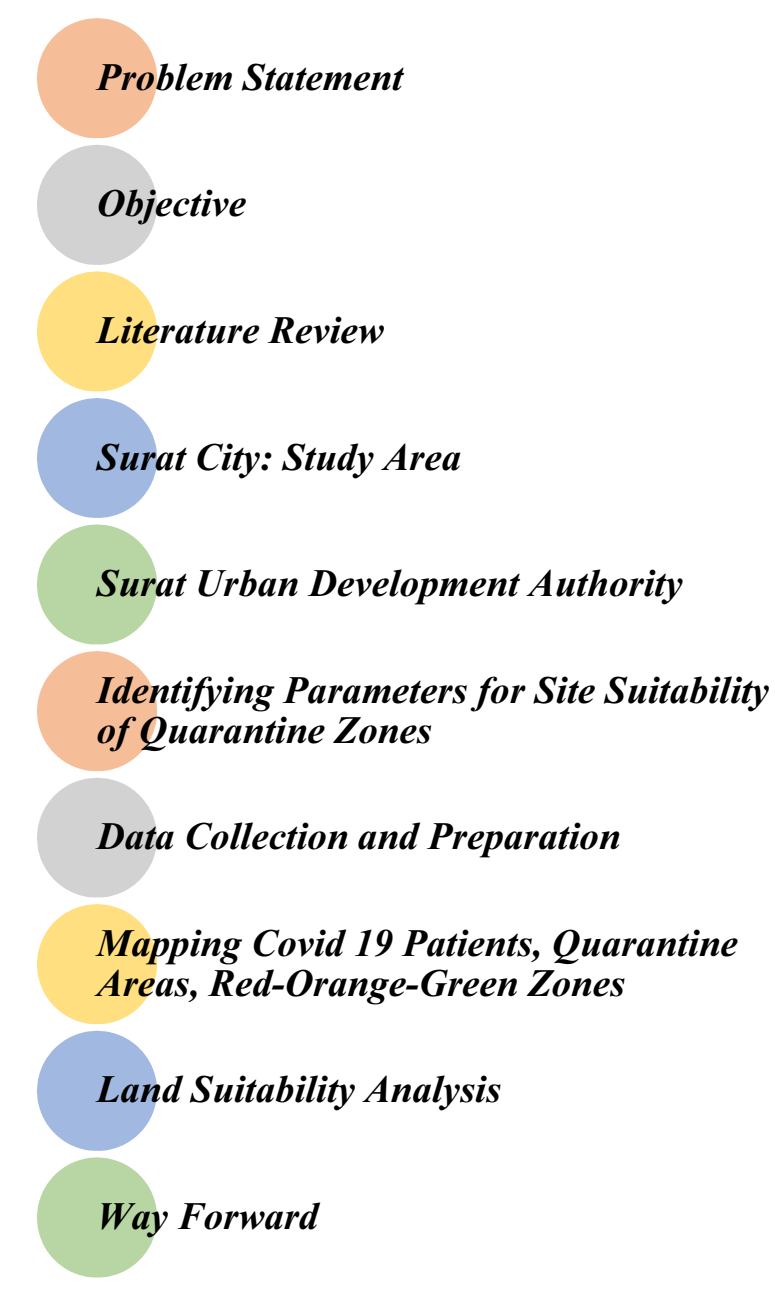

Fig. 1 Methodology adopted for study 
elevation are considered as more influential parameters for urban pandemic spread. Factor maps of all sub-parameters are as shown in Fig. 2.

All the factor maps are taken as input and their weight are entered in weighted sum tool of ArcGIS, and resultant raster map is classified into the five classes, that is, very suitability, suitable, moderately suitable, less suitable and unsuitable as shown in Fig. 3. Real-time mapping of patients, essentials to be supplied, demarking the red zone, orange zone and green zone as per the COVID-19 patients in an area is effectively done on GIS. Spatial interpretation of such data can be very useful for any kind of disaster management in urban planning. Suitable area indicates wards with low risk, unsuitable indicates wards with high risk. Considering all the essentials, travel time to maintain supply chain, the suitability maps provides with potential location.

Figure 4 shows spatial distribution of patients tested positive for COVID-19, along with those discharged and deceased. As per the densities of patients in a ward, the wards are indicated as red, green, and orange ward. Density of positive tested patient is more on the western part of city.

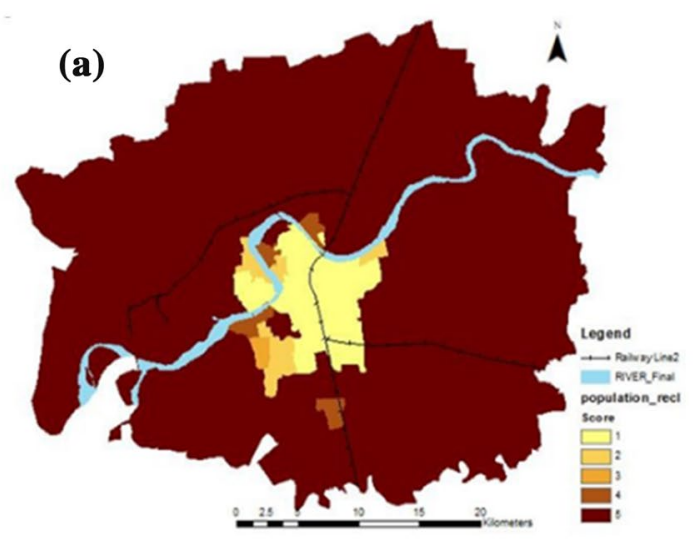

(c)

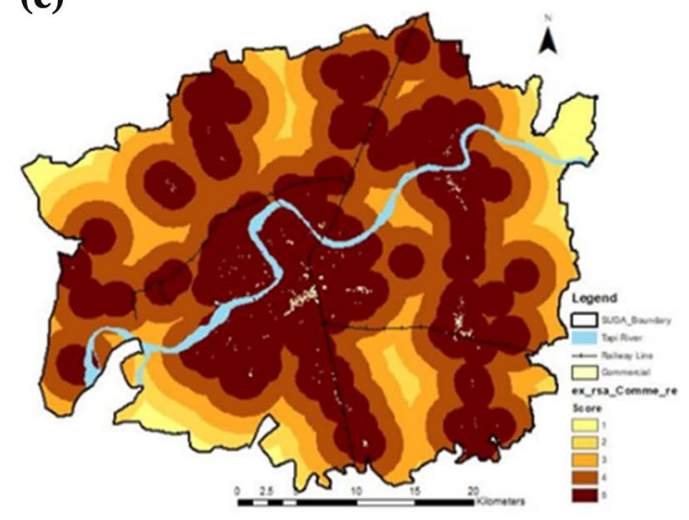

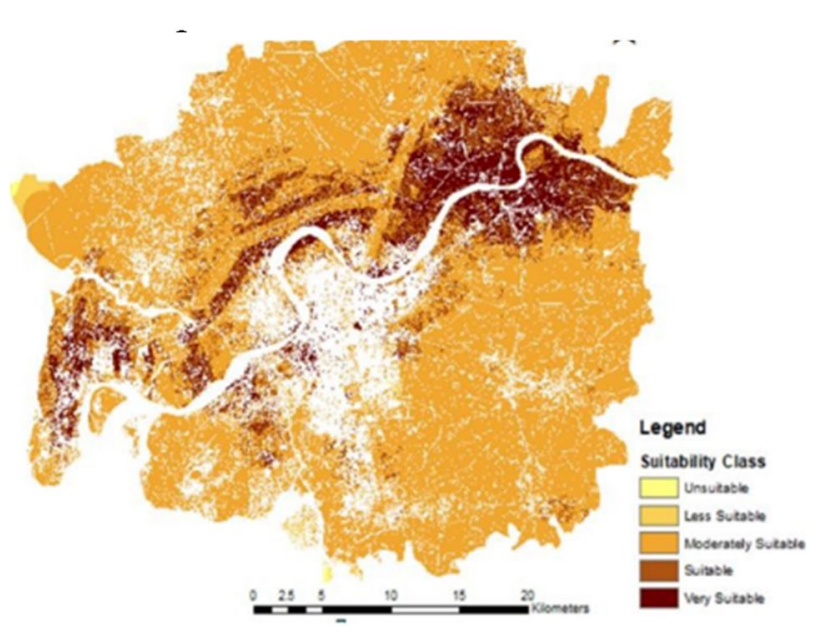

Fig. 3 Land suitability map

Rander ward of city has maximum number of patients. It is denoted as high vulnerable area in red. Such wards should be completely sealed and no movements should be allowed.
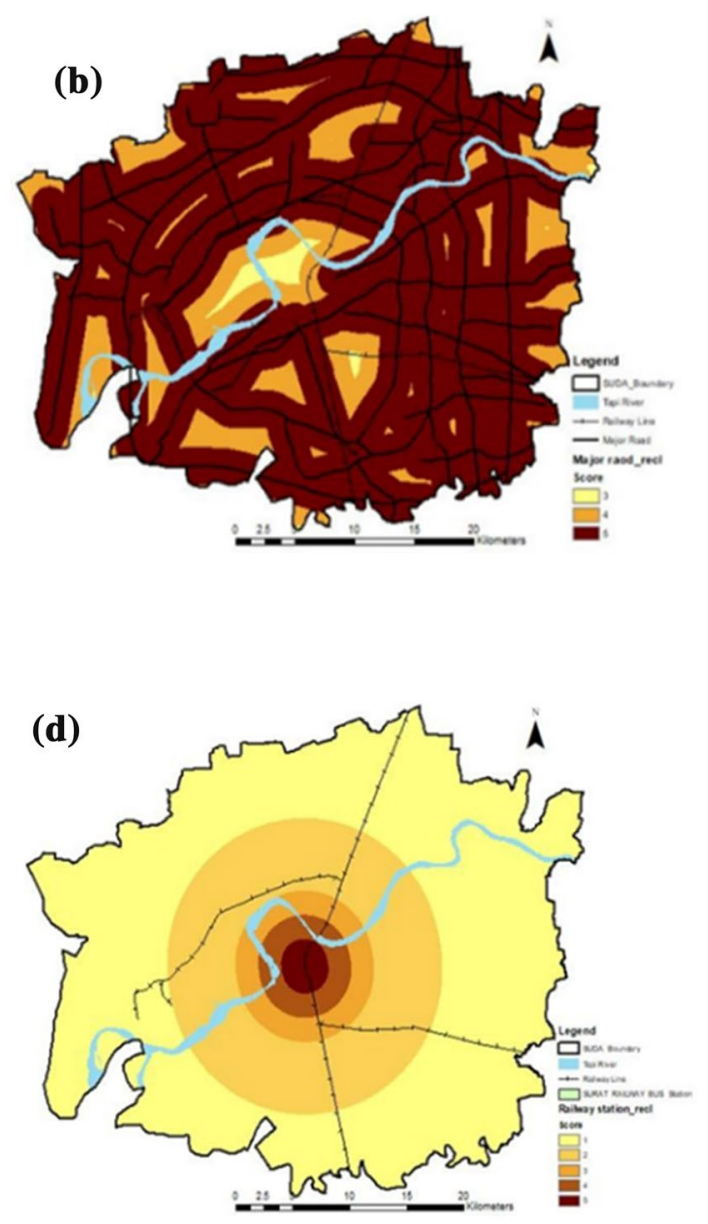

Fig. 2 a Population density, b distance to commercial, $\mathbf{c}$ distance to major road, $\mathbf{d}$ distance to major transportation center 

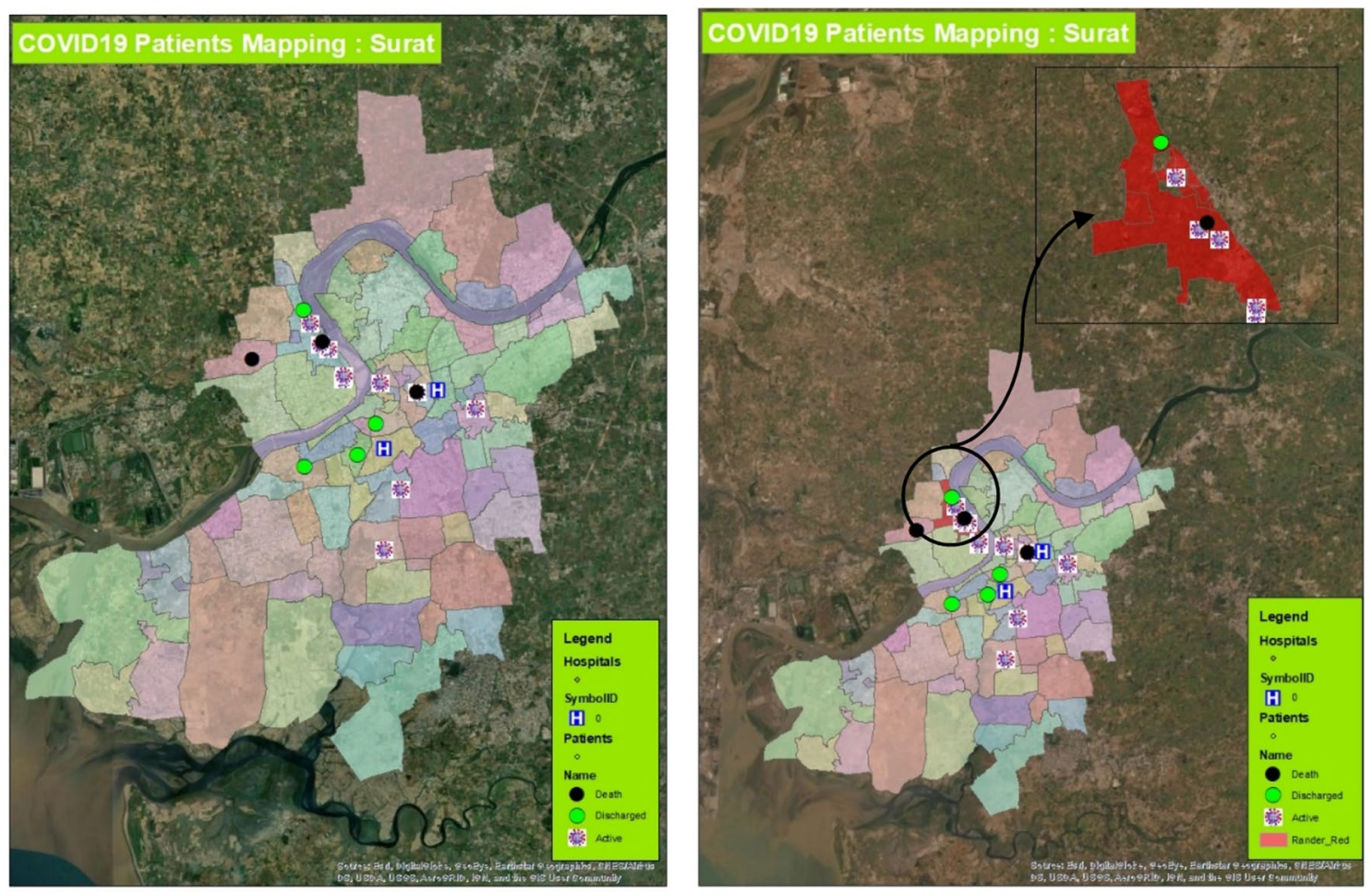

Fig. 4 Surat COVID-19 map

Due to lack of availability of infrastructure, there is a risk for virus to spread in that area, if the people who have been contact are not quarantined. There are about 2834 patients under home quarantine in Surat. For people in contact who do not have permanent shelter and the people who have been in contact with positive tested patients, emergency quarantine centers can be developed on the open spaces/gardens as shown in Fig. 5.

\section{Conclusion}

The use of Geospatial technology can be a major asset for policy makers and urban planners to identify and demarcate the areas with the pandemic effect. The datasets from apps like Aarogya Setu, Municipalities dashboard can be integrated with the spatial resources of cities for extraction information effectively. ESRI along with FEMA are providing free access to data and mapping technology in response to COVID-19. The big data on land-use pattern, population density, major clusters with high and low risk, supply chain points or cluster, transportation nodes for daily essentials supply are very much helpful in managing the impact of the pandemic. The use of such data in Surat city has helped in managing the spread of the COVID-19 effect. Based on the database gathered by the city administration, it was used for mapping clusters which helped in tracking the possible

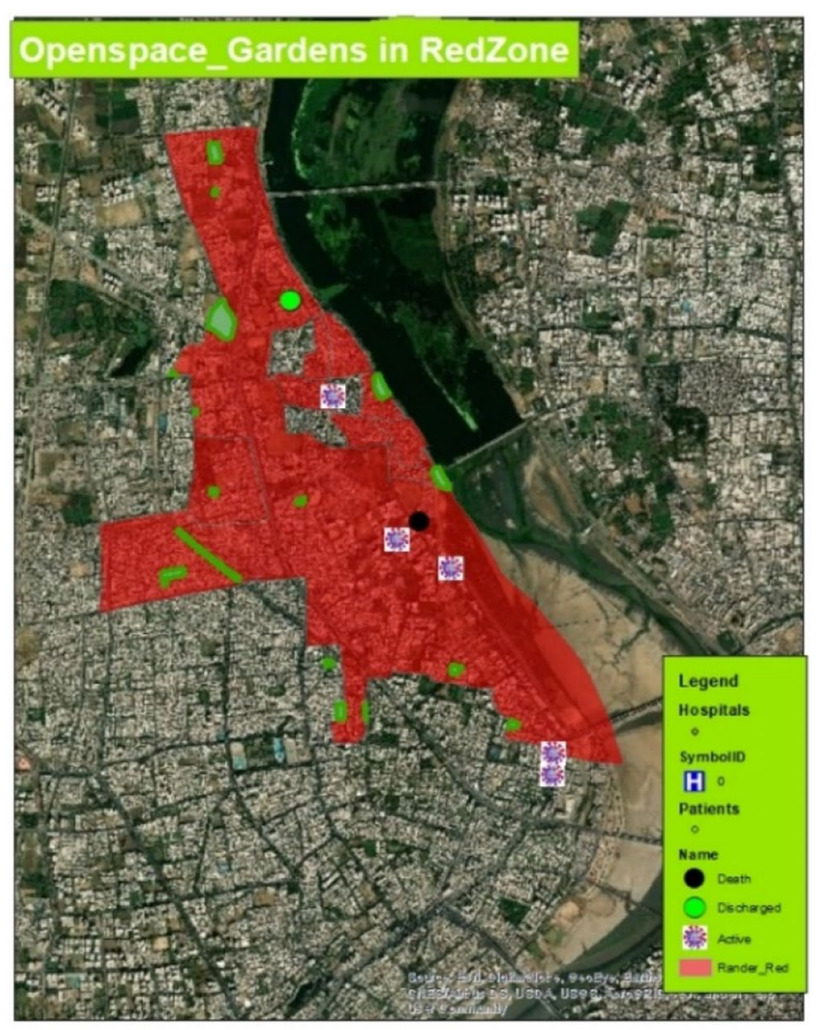

Fig. 5 Red zone of Surat 
containment zone with COVID-19 pandemic. If this kind of technology will be used by all Municipal Corporations in India, then this may help to control the spread. Further, it may help in managing the lockdown and making the supply chain effective by maintaining the social distance too. These types of Geospatial Technology can be used as spatial tool for resource allocation, health center location and land suitability as demonstrated for the above city. Major challenge to the decision maker is the absence of systematic big data and resources for the geospatial technology. Interactive dashboards like that of SMC should also be developed by other cities. Very few Indian Municipalities have shown the data visualization on their websites. Cities like Mumbai, Ahmedabad, Pune, Delhi, etc. which are highly vulnerable to COVID-19 should map COVID-19 related information for better visualization. From now, if the government will focus on spatial infrastructure development along with the physical and social infrastructure development, then in near future, it can be a blessing to the decision makers and they can prevent spreading of pandemic in the nation to have, "Prevention is better then cure"..

\section{References}

Aarogya Setu app downloaded in 9.8 crore smartphones-the New Indian Express. (n.d.). Retrieved May 13, 2020, from https://www. newindianexpress.com/nation/2020/may/11/aarogya-setu-appdownloaded-in-98-crore-smartphones-2142010.html

Arab-Mazar Z, Sah R, Rabaan AA, Dhama K, Rodriguez-Morales AJ (2020) Mapping the incidence of the COVID-19 hotspot in
Iran-implications for travellers. Travel Med Infect Dis. https:// doi.org/10.1016/j.tmaid.2020.101630

coronavirus: How enterprises are using GIS to track COVID-19 impact, IT News, ET CIO. (n.d.). Retrieved April 6, 2020, from https ://cio.economictimes.indiatimes.com/news/strategy-and-manag ement/how-enterprises-are-using-gis-to-track-covid-19-impac $\mathrm{t} / 74821102$

Coronavirus Disease 2019 (2020) Retrieved April 12, 2020, from https ://www.who.int/emergencies/diseases/novel-coronavirus-2019

Kamel Boulos MN, Geraghty EM (2020) Geographical tracking and mapping of coronavirus disease COVID-19/severe acute respiratory syndrome coronavirus 2 (SARS-CoV-2) epidemic and associated events around the world: how 21st century GIS technologies are supporting the global fight against outbreaks and epidemics. Int J Health Geogr 19(1):8. https://doi.org/10.1186/s12942-02000202-8

Legger M (2020) COVID-19 response: GIS best practices in local governmentldata-smart city solutions. https://datasmart.ash.harva rd.edu/news/article/covid-19-response-gis-best-practices-local -government

SMC (2020) Encroachment : Surat municipal corporation. Retrieved April 12, 2020, from https://www.suratmunicipal.gov.in/TheCity/ Introduction

van den Berg R (2020) How will COVID-19 affect urban planning? TheCityFix. Retrieved April 12, 2020, from https://thecityfix.com/ blog/will-covid-19-affect-urban-planning-rogier-van-den-berg/

Zhou C, Su F, Pei T, Zhang A, Du Y, Luo B, Cao Z, Wang J, Yuan W, Zhu Y, Song C, Chen J, Xu J, Li F, Ma T, Jiang L, Yan F, Yi J, Hu Y, Xiao H (2020) COVID-19: challenges to GIS with big data. Geogr Sustain. https://doi.org/10.1016/j.geosus.2020.03.005

Publisher's Note Springer Nature remains neutral with regard to jurisdictional claims in published maps and institutional affiliations. 